\title{
Derived Environment Effects in Colloquial Helsinki Finnish
}

\author{
Arto Anttila \\ Boston University \\ anttila@bu.edu
}

\begin{abstract}
Derived environment behavior is unlikely to be a property of phonological rules of any kind. Reference to global properties of grammar seems inevitable. The evidence comes from a quantitative study of optional Vowel Coalescence in Colloquial Helsinki Finnish based on a corpus of approximately 13,000 naturally occurring vowel sequences. The coalescence rule is blocked in nonderived environments, but only in phonologically and morphologically marked contexts, and dispreferred in derived environments in exactly the same contexts. This mixed behavior arises from the interaction of optimality-theoretic constraints and the assumption that grammars are partial orderings.
\end{abstract}

\section{The problem}

Some phonological rules apply only in derived environments, i.e. across a morpheme boundary or if fed by an earlier phonological rule, but are blocked elsewhere. ${ }^{1}$ This syndrome, known as Nonderived Environment Blocking

\footnotetext{
${ }^{1}$ Earlier versions of this paper were presented at a staff seminar at the Centre for Advanced Studies/Department of English Language and Literature, National University of Singapore (August 1999) and at a Symposium on Variation Theory and Formal Theory at the 28th Conference on New Ways of Analyzing Variation, University of Toronto (October 1999). I thank Young-mee Cho, Vivienne Fong, Gregory Garretson, Tarja Heinonen, Sharon Inkelas, Brett Kessler, Anna Lubowicz, K.P. Mohanan, Tara Mohanan, Carol Neidle, Anthi Revithiadou, Caro Struijke, Cheryl Zoll and two reviewers for comments and/or discussion. I also thank Kotimaisten kielten tutkimuskeskus [Research Institute for
} 
(NDEB), is a traditional puzzle in generative phonology. Familiar textbook examples include English Trisyllabic Shortening which applies in the morphologically derived divin +ity (from divine), but not in the nonderived nightingale. A much-discussed question concerning NDEB is the following:

(1) What alternations are subject to NDEB?

The answers to (1) have traditionally been given in terms of rule typologies:

(2) a. NDEB is a property of non-automatic neutralization rules (The Revised Alternation Condition, RAC, Kiparsky 1973)

b. NDEB is a property of cyclic rules (The Strict Cycle Condition, SCC, Mascaró 1976)

c. NDEB is a property of lexical rules (The Elsewhere Condition, Kiparsky 1982)

d. NDEB is a property of structure-building rules operating on underspecified representations (Kiparsky 1993a)

Kiparsky (1993a) showed that there exist rules that are both cyclic and lexical, yet apply in nonderived environments, contradicting (2b) and (2c). The crucial evidence comes from the rule of Vowel Coalescence (henceforth VC) in Colloquial Helsinki Finnish. This optional rule applies to heterosyllabic two-vowel sequences where both vowels are unstressed and the second vowel is $[+$ low]. An example is given in (3):

(3) Vowel Coalescence in Colloquial Helsinki Finnish:

/makea/ 'sweet': má.ke.a〜má.kee

the Languages of Finland] for the permission to use the electronic version of Nykysuomen sanakirja [Dictionary of Modern Finnish] (Sadeniemi 1973) and the Department of General Linguistics, University of Helsinki, for giving me access to Heikki Paunonen's Spoken Helsinki Finnish Corpus. All errors are mine.

The following abbreviations are used in the glosses: COMP $=$ comparative, INE $=$ inessive, $\mathrm{PAR}=$ partitive, $\mathrm{PL}=$ plural. 
In this paper, I take a closer look at the Finnish evidence in the light of a corpus of spoken Helsinki Finnish collected by Heikki Paunonen and his associates in the early 1970's and documented in Paunonen 1995. The corpus covers 126 speakers grouped by age, sex, social class, and neighborhood, about 500,000 word forms in all. The raw corpus is available at the University of Helsinki Language Corpus Server at http: //www.ling.helsinki.fi/uhlcs. For the purposes of the present study, all the environments relevant to Vowel Coalescence were tagged phonologically and morphologically by the present author, approximately 13,000 vowel sequences in all. ${ }^{2}$

Two theoretically important generalizations emerge:

(4) a. Nonderived EnVIRONMENTS. VC is categorically blocked in nonderived environments if the structural change is highly marked; if the structural change is unmarked, VC may apply even in nonderived environments.

b. Derived environments. VC is statistically dispreferred in derived environments if the structural change is highly marked; if the structural change is unmarked, VC is statistically preferred.

These generalizations do not make immediate sense in rule-based phonology. If NDEB is a property of a class of phonological rules, then one would certainly expect a single rule either to show or not show NDEB. Instead, (4a) states that one and the same rule sometimes does, sometimes doesn't show NDEB, depending on markedness. (4b) is even more puzzling as a rule's application probability is usually not taken to be a matter of grammar at all.

After considering the Finnish evidence in detail, we will come to the conclusion that derived environment behavior cannot be tied to phonological rules of any kind. The reason is that the very same rule may show NDEB in

${ }^{2}$ The tagging had to be done manually because of morphological ambiguities which are common in speech due to reduction phenomena. The following decisions are worth mentioning: (i) Everything was tagged, including the interviewer. Unclear cases, including irresolvable ambiguities, were marked by a special tag and excluded; (ii) Ambiguities that were frequently irresolvable include oikee, either from oikea 'right' or oikein 'really', where only the first is an instance of Vowel Coalescence, and part-of-speech ambiguities like suomalaisia, either 'Finn-PL-PAR, n.' or 'Finnish-PL-PAR, a.'. Such cases are often, but not always, disambiguated by the context; (iii) Sequences of two vowels where either vowel bears primary stress were not tagged (e.g. té.at.te.ri 'theatre', ráu.ta.tie=à.se.ma 'railway station') because they do not meet the structural description of the rule (see below). 
certain contexts, but not in others, depending on markedness. This suggests that reference to global properties of grammar is inevitable, and that rules, i.e. specific phonological processes, cannot serve as the locus of explanation. We will then construct an analysis of the Finnish facts in terms of Optimality Theory (Prince and Smolensky 1993). More specifically, we will propose that NDEB results from root faithfulness (McCarthy and Prince 1995) which is relativized to markedness. A simple partially ordered optimality-theoretic grammar is constructed that predicts both the categorical and quantitative blocking patterns observed in the data, along the lines of Anttila 1997b. Under this view, NDEB turns out to be a categorical special case of quantitative dispreference.

I am deeply indebted to Paunonen's (1995) valuable earlier study of VC based on a slightly different, but largely coextensive subset of the same corpus. While my interpretation of the facts is quite different from his, all of Paunonen's factual observations and most of his generalizations still stand under my reanalysis.

\section{The categorical aspects of VC}

Under the most general formulation, VC applies to any heterosyllabic twovowel sequence, whether underlying or derived, where both vowels are unstressed and the second vowel is [+low].

(5) $\mathrm{V}_{1} \cdot \mathrm{V}_{2} \rightarrow \mathrm{V}_{1}$ : where $\mathrm{V}_{2}=[+\mathrm{low}]$

$\begin{array}{lllll}\text { ea } \rightarrow \text { ee } & \text { má.ke.a } & \rightarrow & \text { má.kee } & \text { 'sweet' } \\ \text { eä } \rightarrow \text { ee } & \text { kí.pe.ä } & \rightarrow & \text { kí.pee } & \text { 'sick' } \\ \text { оa } \rightarrow \text { oo } & \text { ái.no.a } & \rightarrow & \text { ái.noo } & \text { 'only' } \\ \text { öä } \rightarrow \text { öö } & \text { Ýr.jö.-ä } & \rightarrow & \text { Ýr.jöö } & \text { 'George-PAR' } \\ \text { ua } \rightarrow \text { uu } & \text { ká.tu.-a } & \rightarrow & \text { ká.tuu } & \text { 'street-PAR' } \\ \text { yä } \rightarrow \text { yy } & \text { hýö.ty.-ä } & \rightarrow & \text { hýö.tyy } & \text { 'advantage-PAR' } \\ \text { ia } \rightarrow \text { ii } & \text { lá.si.-a } & \rightarrow & \text { lá.sii } & \text { 'glass-PAR' } \\ \text { iä } \rightarrow \text { ii } & \text { kén.k-i.-ä } & \rightarrow & \text { kén.kii } & \text { 'shoe-PL-PAR' }\end{array}$

$\mathrm{VC}$ is genuinely optional in the sense of being variable within an individual. In the following short dialogue [File: sIIm3a], we have four instances of coalescence and four instances of non-coalescence. The same speaker sometimes does, sometimes doesn't apply VC, apparently unpredictably. 
(6) OH: Millasii ihmisii siel käy judoomassa?

/millas-i-a/, /ihmis-i-ä/, /judoa-ma-ssa/

What sort of people practise judo there?

JS: Siel käy iha, nuoria ja vanhojaki.

/nuor-i-a/

Some are really young, but there are old people too.

$\mathrm{OH}:$ Miehiä naisia?

/mieh-i-ä/, /nais-i-a/

Men? Women?

JS: Joo miehii ja naisia.

/mieh-i-ä/, /nais-i-a/

Yes, men and women.

As the last line shows, both the coalesced and hiatus variants may occur within the same NP; more examples are cited in Paunonen (1995:106-7). Even more strikingly, both variants may occur within the same word. The word useampia 'many-COMP-PL-PAR' contains both /ea/ and /ia/. All four logical possibilities are attested:

(7) /usea-mp-i-a/ 'many-COMP-PL-PAR'
a. useampia (no VC, no VC)
b. useempia ( $\mathrm{VC}$, no $\mathrm{VC}$ )
c. useampii (no $\mathrm{VC}, \mathrm{VC}$ )
d. useempii (VC, VC)

However, the randomness is merely apparent. We now turn to the ironclad structural regularities, both categorical and quantitative, that govern variation. The categorical regularities are summarized in (8). The table shows that the NDEB-effect emerges clearly in the IA-column, but not so clearly in the EA-column. 
(8) The general picture. $+=\mathrm{VC}$ may apply, $-=\mathrm{VC}$ may not apply. I $=/ \mathrm{i}, \mathrm{u}, \mathrm{y} /=$ high vowel, $\mathrm{E}=/ \mathrm{e}, \mathrm{o}, \ddot{\mathrm{o}} /=$ mid vowel, $\mathrm{A}=/ \mathrm{a}, \ddot{\mathrm{a}} /=$ low vowel.

\begin{tabular}{|l|l|l|l|}
\hline & & IA & EA \\
\hline NONDERIVED & NOUN & - & $-/+$ \\
& ADJECTIVE & - & + \\
\hline DERIVED & NOUN & + & + \\
& ADJECTIVE & + & + \\
\hline
\end{tabular}

(9) The first generalization:

$\mathrm{VC}$ is blocked in nonderived environments if the first vowel is [+high] (IA).
a. miniä〜*minii 'daughter-in-law'
mini-ä mini-i 'mini-PAR'
b. rasia * 'rasii 'box'
lasi-a lasi-i 'glass-PAR'
c. saippua ${ }^{*}$ saippuu 'soap'
hattu-a hattu-u 'hat-PAR'
d. Pöytyä〜*Pöytyy 'place name'
löyly-ä löyly-y 'steam-PAR'

As (10) shows, derived IA-sequences coalesce, nonderived IA-sequences do not. What we see here is classical derived environment behavior. Now, if NDEB is a property of rules, and the IA II alternation exhibits NDEB, then one would expect the EA $\sim E E$ alternation to do the same, for certainly, under any reasonable rule-based analysis, both alternations should be attributed to one and the same phonological rule. But this is not what we find.

(11) The second generalization:

VC applies across the board if the first vowel is [-high] (EA).
a. hopea hopee 'silver'
b. ainoa ainoo 'only'
Aino-a $\sim$ Aino-o 'female.name-PAR'
c. pimeä pimee 'dark'
nime-ä nime-e 'name-PAR' 
Contrary to all expectations, VC applies to hundreds of nonderived EAstems, all common native words such as pimeä 'dark'. It is exactly this class of words that crucially proves the independence of cyclicity/lexicality and NDEB (Kiparsky 1993a). The fundamental generalization here is that IA-stems show NDEB, EA-stems do not. In other words, the derived environment effect is split along a phonological dimension.

However, there is a group of EA-stems that do show the expected NDEBeffect: recently borrowed nouns. ${ }^{3}$

(13) An exception to the second generalization:

$\mathrm{VC}$ is blocked in nonderived environments if the first vowel is [-high] (EA) and the word is a recently borrowed noun.
a. idea *idee
'idea'
forte-a forte-e
'forte'
b. Korea **Koree
'Korea'
Palme-a Palmee
'Palme-PAR'
c. komitea **komitee
'committee'
cumlaude-a cumlaude-e 'cum laude-PAR'
d. teodikea $*^{*}$ teodikee
'theodicy'
'ukulele-PAR'

Let us briefly speculate on what could have motivated such an exceptional pattern. We begin from the following observation: of stems ending in EA or IA, nouns canonically end in IA, adjectives in EA. The following statistics are extracted from the electronic version of Nykysuomen sanakirja [Dictionary of Modern Finnish] (Sadeniemi 1973):

$\begin{array}{llllll} & \text {-IA } & & -\mathrm{EA} & & \\ \text { Nouns: } & 92.6 \% & {[651]} & 7.4 \% & {[52]} & 100 \% \\ \text { Adjectives: } & 2.2 \% & {[6]} & 97.8 \% & {[273]} & 100 \%\end{array}$

Let us assume that, for purely phonological reasons, IA resists coalescence more than EA. Since for irrelevant historical reasons the vast majority of noun stems end in IA and the vast majority of adjective stems in EA, we have a plausible basis for analogy: the failure of coalescence in IA sequences has been

\footnotetext{
${ }^{3}$ Of the following list, only idea and komitea come from Paunonen's corpus. The rest are based on my own judgments.
} 
reanalyzed as failure of coalescence in nouns. Under this scenario, incoming EA-nouns such as idea 'idea, n.' would simply be imitating the majority of nouns, and those happen to be mostly IA-stems which have independent phonological reasons to resist coalescence. As is typical of analogical change, the regularization does not apply across the board: a small number of native EA-nouns resist the change and only new words succumb to analogy. ${ }^{4}$

A parallel noun/adjective split can be observed in two other rules that affect stem-final low vowels: A-DELETION which deletes stem-final [+low] vowels and A-MUtATion which changes them to rounded mid vowels. Both rules apply before the past tense or plural /i/:

$$
\begin{array}{llll}
\text { a. } a, \ddot{a} \rightarrow \emptyset \quad / \text { muna }+\mathrm{i}+\mathrm{ssa} / & \rightarrow \text { mun-i-ssa } & \text { 'egg-PL-INE' } \\
\text { b. } a, \ddot{a} \rightarrow o, \ddot{o} & / \text { kana }+\mathrm{i}+\mathrm{ssa} / & \rightarrow \text { kano-i-ssa } & \text { 'hen-PL-INE' }
\end{array}
$$

In (16), the choice between the two rules is straightforwardly phonological: deletion occurs after rounded vowels, mutation elsewhere. In trisyllabic stems the phonological condition is lost and morphology takes charge: nouns mutate, adjectives delete. ${ }^{5}$

$$
\begin{array}{lll}
\text { /kihara/ 'curl, n.' } \rightarrow & \text { kiharo }+\mathrm{i}+\text { ssa } \\
\text { /kihara/ 'curly, a.' } \rightarrow \text { kihar }+\mathrm{i}+\mathrm{ssa}
\end{array}
$$

Also in this case, the morphological condition appears to be a recent analogical development. To the best of my knowledge, it was first observed by Karlsson (1978) although weak statistical reflexes of it are already visible in Nykysuomen sanakirja [Dictionary of Modern Finnish] (Anttila 2000).

A possible alternative explanation begins with the observation that virtually all recent borrowings are nouns. Thus, one might suggest that the exceptional pattern has nothing to do with the noun/adjective distinction per se. Instead, one might hypothesize that all recently borrowed stems follow the same pattern, i.e. we have a special loanword phonology. The

\footnotetext{
${ }^{4} \mathrm{~A}$ reviewer asks whether EA-coalescence is also disfavored in nouns that contain EAsequences but end in IA-sequences. There are no such examples in Paunonen's corpus. Nykysuomen sanakirja [Dictionary of Modern Finnish] contains two relevant examples: genealogia 'genealogy' and oseanografia 'oceanography'. According to my intuitions, coalescence is out of the question in both cases (*geneelogia, *oseenografia), confirming the generalization that coalescence is blocked in nonderived recently borrowed nouns.

${ }^{5}$ For a more detailed account of the phonology/morphology interactions involved, see Anttila 2000.
} 
behavior of recently borrowed EA-final adjectives would decide between the two hypotheses, but to the best of my knowledge they do not exist. This story has the unfortunate drawback of not explaining why recent borrowings should exhibit NDEB, rather than not. After all, both models are abundantly available in the language. ${ }^{6}$

In sum, the Colloquial Helsinki Vowel Coalescence rule, which is both cyclic and lexical, turns out to exhibit an unusual split NDEB pattern: in IA-stems, the rule is blocked in nonderived environments; in EA-stems it "overapplies", except in recently borrowed nouns which show NDEB.

Another way to summarize the data pattern in (8) is to state three implications:

(18) Summary:
a. IA $\supset$ EA Coalescence in IA implies coalescence in EA.
b. ND $\supset \mathrm{D}$ Coalescence in nonderived environments implies coalescence in derived environments.
c. $\mathrm{N} \supset \mathrm{A} \quad$ Coalescence in nouns implies coalescence in adjectives.

These three implications capture the distribution of pluses and minuses in (8). (18b) states the weak form of NDEB observed in the Finnish data: if coalescence applies in nonderived environments in some phonologically and morphologically defined class of stems, it also applies in derived environments in the same class of stems.

\section{The statistical aspects of VC}

The most striking aspect of the Helsinki data is that the categorical blocking pattern turns out to have a statistical analogue. ${ }^{7}$ The generalization (19a) is due to Paunonen (1995:111), the generalizations (19b-c) are mine.

\footnotetext{
${ }^{6} \mathrm{~A}$ parallel case is the Polish rule of First Velar Palatalization (Rubach 1984) which palatalizes velars before front vocoids and is blocked in nonderived environments. An interesting observation, attributed to Christina Bethin by Lubowicz (1998:20), fn. 14, is that all these NDEB cases are borrowings: [ke]fir 'kefir', [ke]lner 'waiter', [k'i] siel 'jelly', [ge]ncjana 'gentian', a [ge]nt 'agent', [g'i]ps 'plaster', [x'i] gienistka 'hygienist', [x'i] storia 'history', [xe]tera 'shrew (person)'. In addition, all are nouns.

${ }^{7}$ At this point, I have quantitative data only on the vowel sequences /ea/ and /ia/, which are the two most common mid-low and high-low combinations.
} 

a. IA $\supset$ EA Coalescence is at least as common
in EA as in IA, other things being equal.
b. ND $\supset \mathrm{D}$ Coalescence is at least as common in derived as in nonderived environments, other things being equal.
c. $\mathrm{N} \supset \mathrm{A}$ Coalescence is at least as common in adjectives as in nouns, other things being equal.

First, consider (19a). The words lasi-a 'glass-PAR' and ove-a 'door-PAR' are both derived nouns. The only difference is phonological: -ia vs. -ea. VC applies optionally to both, but is systematically more common in the ove- $a$ type. As Paunonen shows, this generalization is extremely well supported by various types of data. Outside Helsinki, it is reflected in the dialect geography of Finland. In Helsinki, it holds of individual speaker groups, down to the level of idiolects, and also of various morphologically defined word classes, such as partitives and infinitives. In fact, even the behavior of individual words is consistent with the generalization. The word useampia 'many-COMP-PL-PAR' behaves as one might expect:

$$
\text { /usea-mp-i-a/ 'many-COMP-PL-PAR' }
$$

\section{FREQUENCY}
a. useampia (no VC, no VC) 22
b. useempia (VC, no VC) 5
c. useempii (no $\mathrm{VC}, \mathrm{VC}$ ) 3
d. useampii (VC, VC) 1

The unexpected type is (20d) where IA coalesces, but EA does not. There is exactly one such example in the entire corpus. All other examples (30 out of 31) conform to Paunonen's generalization. ${ }^{8}$

The morphological implications (19b) and (19c) also have statistical reflexes. (19b) emerges in pairs like hopea 'silver' and ove-a 'door-PAR'. Both

\footnotetext{
${ }^{8}$ One may wonder how (20d) is possible at all. The explanation hinges on secondary stress. Recall that coalescence requires both vowels to be unstressed. In this case, ú.se.àm.pii is a possible stress pattern and coalescence is blocked because of secondary stress on the third syllable. This has of course been observed by Finnish historical phonologists, see e.g. Rapola 1966:413-27. Unfortunately, at this point I do not yet have serious quantitative data on the secondary stress factor; I intend to return to this topic on another occasion.
} 
are -ea-final nouns. The only difference is morphological: the first word is nonderived, the second derived. VC applies optionally to both, but is systematically more common in the derived ove-a type. Finally, (19c) emerges in pairs like $o v-i-a$ 'door-PL-PAR, n.' and $u u s-i-a$ 'new-PL-PAR, a.' Both are - $i a$-final derived words, but the first is a noun, the second adjective. Again, VC applies optionally to both, but is systematically more common in the uus-i-a type, that is, in adjectives.

All these quantitative generalizations are robust. They hold across different age groups (old, middle-aged, young), social classes (I, II, III), neighborhoods (Töölö, Sörnäinen) and sexes. In other words, no matter how we pick a group of people, the same structural hierarchies emerge. For example, consider the distribution of coalescence by age. The absence of derived -ea-final adjectives can be considered an accidental lexical gap. ${ }^{9}$

(21) Old:

\begin{tabular}{|ll|ll|ll|}
\hline & & $-e a$ & & $-i a$ & \\
\hline $\mathrm{N}$ & $\mathrm{ND}$ & $3.2 \%$ & $(1 / 31)$ & $0 \%$ & $(0 / 337)$ \\
& $\mathrm{D}$ & $24.3 \%$ & $(65 / 267)$ & $7.8 \%$ & $(147 / 1,886)$ \\
\hline $\mathrm{A}$ & $\mathrm{ND}$ & $49.5 \%$ & $(242 / 489)$ & $0 \%$ & $(0 / 80)$ \\
& $\mathrm{D}$ & - & - & $9.6 \%$ & $(146 / 1,519)$ \\
\hline
\end{tabular}

(22) Middle-aged:

\begin{tabular}{|ll|ll|ll|}
\hline & & $-e a$ & & $-i a$ & \\
\hline N & ND & $18.2 \%$ & $(4 / 22)$ & $0 \%$ & $(0 / 263)$ \\
& D & $30.5 \%$ & $(60 / 197)$ & $11.4 \%$ & $(182 / 1,597)$ \\
\hline A & ND & $64.8 \%$ & $(333 / 514)$ & $0 \%$ & $(0 / 100)$ \\
& D & - & - & $16.8 \%$ & $(220 / 1,308)$ \\
\hline
\end{tabular}

(23) Young:

\begin{tabular}{|ll|ll|ll|}
\hline & & $-e a$ & & $-i a$ & \\
\hline $\mathrm{N}$ & $\mathrm{ND}$ & $50 \%$ & $(4 / 8)$ & $0 \%$ & $0 / 247$ \\
& $\mathrm{D}$ & $67.2 \%$ & $(168 / 250)$ & $43.5 \%$ & $(685 / 1,576)$ \\
\hline $\mathrm{A}$ & $\mathrm{ND}$ & $93.0 \%$ & $(687 / 739)$ & $0 \%$ & $(0 / 81)$ \\
& $\mathrm{D}$ & - & - & $64.2 \%$ & $(923 / 1,437)$ \\
\hline
\end{tabular}

\footnotetext{
${ }^{9}$ An example of an /e/-final adjective is /toope/ 'stupid', in the partitive singular /toope-a/. While Paunonen's corpus contains no examples of this word, according to my intuitions this word clearly coalesces: toope-e 'stupid-PAR'.
} 
In each age group, -ea coalesces more than - $i a$, derivedness and part of speech being equal; derived words coalesce more than nonderived words, phonology and part of speech being equal; and adjectives coalesce more than nouns, derivedness and phonology being equal. In other words, the structural hierarchies hold perfectly. Crucially, their surface reflexes are sometimes categorical, sometimes statistical.

How did this pattern arise? Another look at the figures shows that age has a systematic effect on coalescence frequencies: young speakers apply coalescence more than middle-aged apeakers, who in turn apply coalescence more than old speakers. Whether this reflects change in progress or agegrading is not obvious. In his discussion of the possible historical scenarios, Paunonen (1995:122-32) first suggests the possibility that Vowel Coalescence reflects a historical change that started from EA-words, this being phonetically the most natural environment for coalescence, and moved on to IAwords along various morphological dimensions, which would explain the IA $\supset$ EA asymmetry. However, he hastens to point out that regular development is inconsistent with the demographic and dialectological facts. Spoken Helsinki Finnish emerged from a recent confluence of dialects that occurred over a very short period of time. Thus, it is all the more striking that the end result should be structurally so systematic, down to subtle statistical tendencies. Paunonen (1995:132) concludes that this can only be attributed to the influence of 'language-internal causal connections' (sisäinen vaikutusyhteys), or put slightly differently, (universal) grammar.

To sum up, we have discovered three structural hierarchies that emerge consistently in the data. Their combined surface effect is sometimes a categorical rule, sometimes a statistical tendency.

(24) a. Coalescence is more likely in EA than IA. The result may be categorical blocking: hopea hopee 'silver, n.' vs. rasia ${ }^{*}$ rasii 'box, n.'

b. Coalescence is more likely in derived forms than nonderived forms. The result may be categorical blocking: mini-ä mini- $i$ 'mini-PAR, n.' vs. minï̈ ${ }^{*}$ minii 'daughter-in-law, n.'

c. Coalescence is more likely in adjectives than nouns. The result may be categorical blocking: korea $\sim$ koree 'beautiful, a.' vs. Korea $\sim^{*}$ Koree 'Korea, n.' 
Table (25) shows the eight possible factor combinations and the observed results. The factors disfavoring coalescence appear in boldface (IA, ND, $\mathbf{N})$. The coalescence rates are given in two ways: as ranges covering the ten groups (three age groups, three social classes, two neighborhoods, two sexes) and as the average coalescence rate in the entire corpus.

(25) $\mathrm{OBS}_{1} \%=$ the observed range of variation (10 groups)

$\mathrm{OBS}_{2} \%=$ the observed coalescence rate in the total corpus

$\begin{array}{llllllll} & & & & \text { VC } & \text { OBs }_{1} \% & \text { OBs }_{2} \% & \text { TotAL } \\ \text { 1. } & \text { EA } & \text { D } & \text { A } & \text { applies } & - & - & 0 \\ \text { 2. } & \text { EA } & \text { ND } & \text { A } & \text { applies } & 49.5-93.0 \% & 72.4 \% & 1,742 \\ \text { 3. } & \text { EA } & \text { D } & \text { N } & \text { applies } & 24.3-67.2 \% & 41.0 \% & 714 \\ \text { 4a. } & \text { EA } & \text { ND } & \text { N } & \text { applies } & 0-66.7 \% & 27.3 \% & 33 \text { (native) } \\ \text { 4b. } & & & & \text { NDEB } & 0 \% & 0 \% & 12 \text { (borrowing) } \\ \text { 5. } & \text { IA } & \text { D } & \text { A } & \text { applies } & 9.6-64.2 \% & 30.2 \% & 4,264 \\ \text { 6. } & \text { IA } & \text { D } & \text { N } & \text { applies } & 7.8-43.5 \% & 20.0 \% & 5,059 \\ \text { 7. } & \text { IA } & \text { ND } & \text { A } & \text { NDEB } & 0 \% & 0 \% & 261 \\ \text { 8. } & \text { IA } & \text { ND } & \text { N } & \text { NDEB } & 0 \% & 0 \% & 847\end{array}$

Categorical blocking emerges if coalescence is disfavored by at least two factors. In order to get blocking in EA-stems, we need both morphological criteria to weigh against coalescence and even then the pattern remains lexically restricted. In IA-stems blocking is more widespread; here nonderivedness is by itself sufficient. We also note that while nonderivedness is not a sufficient condition for blocking, it is a necessary one, whereas being a noun is neither. In this sense, of the two morphological conditions, nonderivedness is the stronger one in disfavoring the rule's application.

There is one surprising fact in table (25). As the percentages in $(2-3)$ show, among EA-stems nonderived adjectives coalesce at a higher rate than derived nouns. If phonology and morphology were mutually independent, one would expect the same ordering to emerge in IA-stems, but this is not what we find. As lines (6-7) show, here the ordering is reversed: derived nouns coalesce at a higher rate than nonderived adjectives, which in fact never coalesce, but exhibit categorical blocking. What this means is that phonological and morphological constraints depend on each other. This is somewhat surprising given the normal assumption that linguistic variables are mutually independent (Cedergren and Sankoff 1974:337). This unexpected fact will have direct consequences for the design of the phonology/morphology interface, as we will see in a moment. 
Our main conclusion is that the total blocking of an alternation is the categorical limiting case of quantitative dispreference that occurs in phonologically and/or morphologically highly marked environments.

\section{An optimality-theoretic analysis}

We will now proceed to give an optimality-theoretic analysis of the unusual NDEB pattern in Colloquial Helsinki Finnish. This will entail taking a stand on two important questions:

(26) a. What is the nature of NDEB?

b. What is the grammatical status of quantitative regularities?

First, we introduce the general approach by accounting for the purely phonological vowel height effect (EA vs. IA) in terms of an optimalitytheoretic grammar where the ranking is not a TOTAL but a PARTIAL ORDER. Partial ordering (called "crucial nonranking") was mentioned by Prince and Smolensky (1993:51) as a formal possibility provided by the theory for which no evidence existed at the time. Its empirical relevance was pointed out in Kiparsky's (1993b) unpublished work on English $t$, $d$-deletion, and it has since been successfully applied to several cases of statistical variation, e.g. Reynolds 1994, Nagy and Reynolds 1997, Anttila 1997a, Anttila and Cho 1998, Ringen and Heinämäki 1999, among others.

Second, we turn to the morphological side of the problem. We consider four possible ways of integrating the derived environment effect into the phonological analysis: (i) local conjunction of markedness and faithfulness (Eubowicz 1998); (ii) cophonologies, i.e. derived and nonderived lexical items participate in different rankings; (iii) root faithfulness, i.e. roots are more resilient under markedness pressure than affixes (McCarthy and Prince 1995); (iv) underspecification, i.e. alternating vowels are underspecified, nonalternating vowels (NDEB) are fully specified (Kiparsky 1993a, Inkelas to appear). We will choose root faithfulness as the most satisfactory one of the four options. We then consider the apparently very similar noun/adjective effect. This time, the evidence favors the cophonology hypothesis, which implies that the part-of-speech effect can be attributed to analogy. 


\subsection{The phonological effect}

We first derive the vowel height asymmetry, both in its categorical and statistical manifestations. Dialects of the categorical type include Literary Finnish where neither EA nor IA coalesce, and the system of old female upper middle class Töölö residents who allow coalescence optionally in EA, but never in IA (Paunonen 1995:112). We start by assuming the following phonological constraints:

(27) Constraints:

$\begin{array}{lll}{ }^{*} \text { EA } & \text { Avoid /ea, oa, öä/ hiatus. } & \text { (markedness) } \\ { }^{*} \text { IA } & \text { Avoid /ia, ua, yä/ hiatus. } & \text { (markedness) } \\ \text { FAITH } & \text { No coalescence. } & \text { (faithfulness) }\end{array}$

I follow Paunonen in assuming that $e a \rightarrow e e$ is a phonologically more natural process than $i a \rightarrow i i$ which can be expressed as the ranking $* \mathrm{EA} \gg$ ${ }^{*}$ IA. ${ }^{10}$ This yields a typology of three totally ranked grammars. Two of the corresponding dialects are found in Paunonen 1995:109. While Paunonen's descriptions of regional dialects are obviously simplifications, they will serve for illustrative purposes here.

(28) No coalescence (conservative dialect, Literary Finnish):

\begin{tabular}{|c|c|c|c|c|}
\hline & $|-\mathrm{ea}|$ & FAITH & ${ }^{*} \mathrm{EA}$ & $* \mathrm{IA}$ \\
\hline 1a. $\Rightarrow$ & $\mid /$-ea/ & & * & \\
\hline 1b. & $\mid-\mathrm{ee} /$ & $* !$ & & \\
\hline 2a. $\Rightarrow$ & /-ia/ & & & $*$ \\
\hline $2 \mathrm{~b}$ & /-ii/ & $* !$ & & \\
\hline
\end{tabular}

(29) Coalescence only in mid vowels (General Häme):

\begin{tabular}{|c|c|c|c|c|}
\hline & /-ea/ & ${ }^{*} \mathrm{EA}$ & FAITH & $* \mathrm{IA}$ \\
\hline 1 a. & $\overline{\mid l-e a /}$ & *! & & \\
\hline 1b. $\Rightarrow$ & $\mid-\mathrm{ee} /$ & & $*$ & \\
\hline 2a. $\Rightarrow$ & /-ia/ & & & $\overline{* *}$ \\
\hline $2 \mathrm{~b}$ & /-ii/ & & $* !$ & \\
\hline
\end{tabular}

\footnotetext{
${ }^{10}$ The constraints *EA and *IA are deliberately noncommittal as to the exact nature of this asymmetry which is found in other languages as well (Haas 1988). It is possible that /i.a/ has a better syllable contact than /e.a/, or that high vowels do not spread as easily as mid vowels (Pulleyblank 1988).
} 
(30) Only coalescence (advanced dialect, not yet found)

\begin{tabular}{|c|c|c|c|c|}
\hline & $/$-ea/ & ${ }^{*} \mathrm{EA}$ & ${ }^{*} \mathrm{IA}$ & FAITH \\
\hline 1a. & $\mid-$-ea/ & $* !$ & & \\
\hline 1b. $\Rightarrow$ & $\mid-\mathrm{ee} /$ & & & $*$ \\
\hline $2 \mathrm{a}$. & /-ia/ & & $* !$ & \\
\hline 2b. $\Rightarrow$ & /-ii/ & & & $*$ \\
\hline
\end{tabular}

This simple three-constraint system generalizes straightforwardly to statistical regularities if we assume that any partial ordering of constraints is a possible grammar. Let $C$ be the set of constraints and $R$ a binary ranking relation with the following properties:

(31) (a) Irreflexivity. $R$ is irreflexive if and only if for every $x$ in $C$, $R$ contains no ordered pair $\langle x, x\rangle$ with identical first and second members. (No constraint can be ranked above or below itself.)

(b) Asymmetry. $R$ is asymmetric if and only if for any ordered pair $\langle x, y\rangle$ in $R$ the pair $\langle y, x\rangle$ is not in $R$. (If $x$ is ranked above $y$, it cannot be ranked below $y$.)

(c) Transitivity. $R$ is transitive if and only if for all ordered pairs $\langle x, y\rangle$ and $\langle y, z\rangle$ in $R$, the pair $\langle x, z\rangle$ is also in $R$. (If $x$ is ranked above $y$ and $y$ is ranked above $z$, then $x$ is ranked above $z$.)

The properties $(31 \mathrm{a}-\mathrm{c})$ define a partial order. In Optimality Theory, grammars are usually assumed to have the additional property of CONNECTEDNESS which requires that, for every two distinct constraints $x$ and $y$ in $C$, $\langle x, y\rangle \in R$ or $\langle y, x\rangle \in R$, i.e. every constraint is ranked with respect to every other constraint. This defines a total ordering, or a tableau.

If we assume that any partial ordering is a possible grammar, we get three more grammars. The resulting typology of six grammars is displayed in diagram (32). The grammars are described as sets of ordered constraint pairs and grouped into natural classes by shared rankings. 


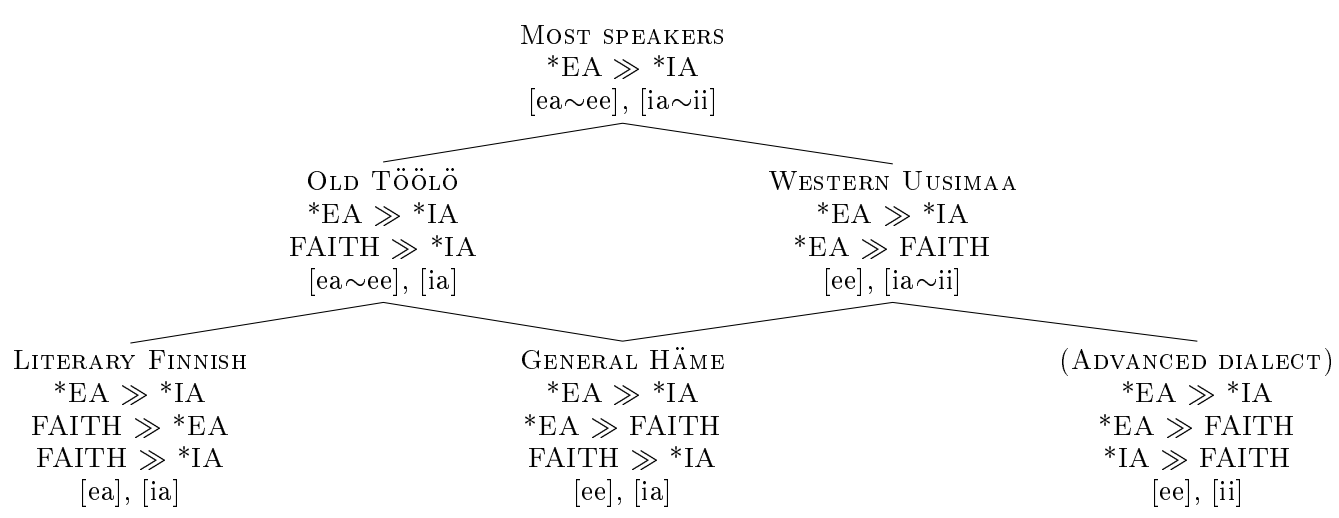

An important consequence of adopting partially ordered grammars is that it becomes possible for grammars to include other grammars. ${ }^{11}$ This is visually represented in diagram (32) in terms of immediate dominance relations. Consider the grammars labeled Most speakers and Old Töölö. The labels are mnemonic: we will soon see that the first grammar is a rough approximation of the grammar of most speakers, the second is the grammar of old female upper middle class Töölö residents. (33) and (34) display these two grammars in two equivalent ways: as ordered pairs of constraints and as totally ordered tableaux.

(33) Most Speakers:

Ordered pairs: $\left\{{ }^{*} \mathrm{EA} \gg{ }^{*} \mathrm{IA}\right\}$

Tableaux:

\begin{tabular}{|c|c|c|c|}
\hline *EA & *IA & $\overline{\text { FAITH }}$ & \\
\hline${ }^{*} \mathrm{EA}$ & FAITH & ${ }^{*} \mathrm{IA}$ & \\
\hline$\overline{\text { FAITH }}$ & ${ }^{*} \mathrm{EA}$ & *IA & \\
\hline
\end{tabular}

(34) Old TööLÖ:

Ordered pairs: $\left\{{ }^{*} \mathrm{EA} \gg{ }^{*} \mathrm{IA}\right.$, FAITH $\left.\gg * \mathrm{IA}\right\}$

\begin{tabular}{|c|c|c|c|}
\hline Tableaux: & *EA & FAITH & *IA \\
\hline & FAITH & $* \mathrm{EA}$ & *IA \\
\hline
\end{tabular}

\footnotetext{
${ }^{11}$ In other words, partially ordered grammars are ordered by the subset relation, itself a partial ordering.
} 
In terms of totally ordered tableaux, MOST SPEAKERS properly includes OLD TööLÖ. In terms of ordered pairs of constraints, OLD TööLÖ properly includes Most SPEAKERS. Speaking in the tableau idiom, we will say that the grammar OLD TöÖLÖ is a SUBGRAMMAR of the grammar MosT SPEAKERS. The fact that grammars may literally include other grammars will be exploited in this paper in various ways.

Now, consider the outputs of these two grammars. OLD TöÖLÖ consists of two tableaux: the first predicts coalescence in EA-stems, the second predicts no coalescence anywhere. We interpret this empirically as follows: in OLD TÖÖLÖ coalescence is optionally allowed in EA-stems, but prohibited in IA-stems. Next, consider Most speAkers. This time, we have three tableaux: one predicts coalescence in IA-stems, two predict coalescence in EA-stems. The empirical intepretation we will adopt here is straightforward: both vowel sequences may coalesce, but EA-stems coalesce more than IA-stems. More specifically, we will assume the following quantitative interpretation of partial ordering (Anttila 1997a):

(35) Quantitative interpretation. (i) A candidate is predicted by the grammar iff it wins in some tableau; (ii) If a candidate wins in $n$ tableaux and $t$ is the total number of tableaux, then the candidate's probability of occurrence is $n / t$.

Given this interpretation, the grammar MOST SPEAKERS thus predicts a pattern where EA coalesces in $2 / 3$ and IA in $1 / 3$ of the cases. This is roughly the statistical profile of Paunonen's total corpus of approximately 11,000 vowel sequences (Paunonen 1995:110): $\mathrm{EA} \rightarrow \mathrm{EE} \mathrm{63.1 \% ;} \mathrm{IA} \rightarrow$ II $29.8 \%$.

\subsection{The NDEB effect}

We have now introduced the general assumptions of our analysis and generated a phonologically plausible typology of six dialects, but have not yet addressed the morphological facts, the most important of which is the NDEB effect. At present, the constraints apply indiscriminately to both derived and nonderived forms, predicting many incorrect outputs, e.g. optional coalescence in the nonderived rasia $\sim^{*}$ rasii 'box' by MOST SPEAKERS, something never found in any dialect.

A novel optimality-theoretic solution to the derived environment problem has been proposed by Łubowicz (1998) who suggests that NDEB-effects 
can be derived from the LOCAL CONJUNCTION of markedness and faithfulness constraints (Smolensky 1995). This may well be the correct analysis of the phonological part of the derived environment generalization. What is immediately relevant in our case, however, is the morphological part of the proposal, also formulated in terms of local conjunction. Its intuitive content can be informally summarized as follows: if a stem-final consonant gets grouped into the same syllable with a suffix-initial vowel (.C+V.), this results in a stem/syllable misalignment which triggers the rule; within roots no stem/syllable misalignment occurs, hence the rule is blocked. Thus, according to Eubowicz, the common denominator of morphological derived environment effects is stem/syllable misalignment. Unfortunately, this does not hold true of the Finnish Vowel Coalescence rule. The stem and syllable edges are perfectly aligned in cases like o.ve.-a 'door-PAR'. We would thus expect coalescence not to take place, but it does. ${ }^{12}$

Another possibility would be to suggest that, just as different dialects are obviously affiliated with different grammars, in the same way different morphological categories may subscribe to different COPHONOLOGIES within an individual's system. ${ }^{13}$ For various uses of cophonologies, see e.g. McCarthy and Prince 1993, Itô and Mester 1995a, 1995b, 1998, Orgun 1996, Inkelas et al. 1997, Inkelas 1998, Anttila 2000 and Anttila and Revithiadou 2000. Thus, for example, we could say that most speakers use the grammar $\left\{{ }^{*} \mathrm{EA}\right.$ $\left.\gg{ }^{*} \mathrm{IA}\right\}$ for general purposes, but its subgrammar $\left\{{ }^{*} \mathrm{EA} \gg{ }^{*} \mathrm{IA}, \mathrm{FAITH} \gg\right.$ *IA\} for nonderived roots, with the notable exception of old female upper middle class Töölö residents who have generalized this subgrammar to all stems, derived and nonderived.

The question now arises: why would nonderived roots select a particular ranking instead of some other ranking? For example, why would nonderived roots not choose the grammar labelled ADVANCED DIALECT which predicts coalescence everywhere? Indeed, why don't we have derived environment blocking? No principled answer is forthcoming. As an explanation of NDEB,

\footnotetext{
${ }^{12}$ An analogous example is Basque final vowel raising (Hualde 1989), discussed in Inkelas to appear.

${ }^{13}$ I use the term "cophonology" to refer to any subgrammar of a given language. Of two cophonologies, one may or may not be a subgrammar of the other. There are obvious similarities between cophonologies, the LEvels of Lexical Morphology and Phonology (Kiparsky 1982, Mohanan 1986, Kiparsky in press) and lexical STRATA in languages like Japanese, as analyzed in Itô and Mester 1995a, 1995b, 1998.
} 
cophonologies seem descriptive and arbitrary. ${ }^{14}$

A third alternative is to assume that NDEB arises from a specialized faithfulness constraint $\mathrm{FAITH}_{\text {root }}$ that requires faithfulness to roots. For other versions and uses of this constraint, see e.g. McCarthy and Prince 1995, Beckman 1998 and Alderete 1999. Under this scenario, coalescence in nonderived forms would result in a violation of $\mathrm{FAITH}_{\text {root }}$ (rasia/*rasii 'box'), whereas coalescence in morphologically derived forms would not violate FAITH $_{\text {root }}$ (lasi-a lasii 'glass-PAR'). For a somewhat different faithfulness-driven approach to NDEB, see Burzio 1998.

While perhaps not the general solution, FAITH $_{\text {root }}$ fares better than its competitors in explaining the Finnish blocking facts. To derive the categorical NDEB-effect in IA-stems, it suffices to rank FAITH $_{\text {root }}$ above the markedness constraint ${ }^{*}$ IA. This yields the subtler dialect typology in (36). Coalesced forms appear in boldface.

(36) Rankings: ${ }^{*} \mathrm{EA} \gg *{ }^{*} \mathrm{IA}, \mathrm{FAITH}_{\text {root }} \gg * \mathrm{IA}$

\begin{tabular}{|c|c|c|c|c|}
\hline . FAITH $\gg * \mathrm{EA} \gg \mathrm{FAITH}_{\text {root }} \gg * \mathrm{IA}$ & $\begin{array}{l}\text { /ove-a/ } \\
\text { ove-a }\end{array}$ & $\begin{array}{l}\text { /hopea/ } \\
\text { hopea }\end{array}$ & $\begin{array}{l}\text { /lasi-a/ } \\
\text { lasi-a }\end{array}$ & $\begin{array}{l}\text { /rasia/ } \\
\text { rasia }\end{array}$ \\
\hline FAITH $\gg$ FAITH $_{\text {root }} \gg * \mathrm{EA} \gg{ }^{*} \mathrm{IA}$ & ove-a & hopea & lasi-a & \\
\hline . FAITH $_{\text {root }} \gg$ FAITH $\gg{ }^{*} \mathrm{EA} \gg{ }^{*} \mathrm{IA}$ & ove-a & hopea & lasi-a & isia \\
\hline 4. $\mathrm{FAITH}_{\text {root }} \gg * \mathrm{EA} \gg \mathrm{FAITH} \gg * \mathrm{IA}$ & ove-e & hopea & lasi-a & \\
\hline 5. $\mathrm{FAITH}_{\text {root }} \gg * \mathrm{EA} \gg * \mathrm{IA} \gg \mathrm{FAITH}$ & ove-e & & lasi-i & \\
\hline$* \mathrm{EA} \gg \mathrm{FAITH} \gg \mathrm{FAITH}_{\text {root }} \gg *$ IA & ove-e & hopee & lasi-a & asia \\
\hline$* \mathrm{EA} \gg \mathrm{FAITH}_{\text {root }} \gg \mathrm{FAITH} \gg *$ IA & ove-e & hopee & lasi-a & \\
\hline$* \mathrm{EA} \gg \mathrm{FAITH}_{\text {root }} \gg *$ IA $\gg$ FAITH & ove-e & hopee & lasi-i & rasia \\
\hline
\end{tabular}

Instead of three, we now predict five distinct categorical systems:

(37) a. No coalescence (1-3).

b. Coalescence in derived EA-environments (4).

c. Coalescence in all derived environments (5).

d. Coalescence in EA-environments, derived and underived (6-7).

e. Coalescence everywhere but underived IA-environments (8).

\footnotetext{
${ }^{14}$ As a reviewer correctly points out, no advocate of cophonologies has ever used them to explain nonderived environment blocking. The same reviewer also asks what it would look like if a rule or constraint applied only in nonderived environments, and suggests it would look like a morpheme structure condition, and those abound. However, it is easy to imagine a dialect of Finnish where coalescence would apply optionally in roots (rasia rasii 'box'), but not in derived forms (lasi-a/*lasii 'glass-PAR'). No such dialects exist and we must explain why.
} 
In addition to these categorical systems, the partial ordering in (36) hides a large number of variable dialects. The following properties hold of them all: 15

(38) All else being equal ( $\geq=$ 'is at least as likely to coalesce as'):
a. $\mathrm{EA}_{N D} \geq \mathrm{IA}_{N D}$
b. $\mathrm{EA}_{D} \geq \mathrm{IA}_{D}$
c. $\mathrm{EA}_{D} \geq \mathrm{EA}_{N D}$
d. $\mathrm{IA}_{D} \geq \mathrm{IA}_{N D}$

Interestingly, prediction (38c) "Derived EA-words are at least as likely to coalesce as nonderived EA-words" is explicitly claimed to be false by Paunonen. According to him, EA-coalescence is systematically more common in (nonderived) nominals than (derived) partitives, which according to him holds true in all speaker groups, except for one with one exceptional speaker. What is even more interesting, these observations follow from his theory. Paunonen's explanation is based on the assumption that historical change avoids creating complexity in morphological rule systems:

The alternation korkea korkee 'high', ainoa ainoo 'only' [in nonderived words, A.A.] thus only concerns the shape of a single lexeme, whereas in partitives [in derived words, A.A.] the alternation between coalesced and hiatus forms would entail increasing complexity in the morphological rule system. From this point of view, the sound development $e a, e \ddot{a}>e e$ and $o a>o o$ is freer to proceed in $e a$, oa nominals than in partitives. For this reason, one would expect that in $e a, e \ddot{a}$ nominals the coalescence forms would be more common than in $e a, e \ddot{a}$-final partitives. Indeed, this is the case. (Paunonen 1995:141) [Translation mine, A.A.]

\footnotetext{
${ }^{15}$ Given the following reasoning: Every partial order can be identified with some subset of the tableaux in (36) (although the reverse does not hold); since the implications hold of every individual tableau, they must hold of any combination of tableaux, which means that they must hold of every partial order.

Also consider some predictions that are not made. Grammar 5 predicts a dialect where /hopea/ does not coalesce, but /lasi-a/ does. This means that EA $\geq$ IA is not expected to hold without qualification. Similarly, Grammars 6-7 predict dialects where the nonderived /hopea/ coalesces, but the derived /lasi-a/ does not, which means that D $\geq$ ND is not expected to hold without qualification.
} 
Needless to say, Paunonen's observations, and consequently his explanation, flatly contradict ours. If correct, they would force us to retreat to the cophonology hypothesis dismissed earlier as descriptive and arbitrary. However, a closer look at the data shows that there is no need to weaken our claim. While perfectly accurate, Paunonen's word counts do not distinguish nouns from adjectives. As noted earlier, virtually all EA-final nonderived forms, e.g. makea 'sweet', are adjectives, and virtually all EA-final derived forms, e.g. ove- $a$ 'door-PAR', are nouns. In other words, the tendency of makea 'sweet' to coalesce more than ove- $a$ 'door' is not because the first is nonderived and the second derived; it is because the first is an adjective and the second a noun. This strong part-of-speech effect is hidden in Paunonen's word counts, and once teased apart, the evidence turns out to be consistent with the root faithfulness hypothesis.

Yet another possibility is to derive to NDEB from representational assumptions, in particular UNDERSPECIFICATION, following Kiparsky (1993a) and Inkelas (to appear). We will put this alternative on hold and take it up after we have discussed the part-of-speech effect. At this point, we will tentatively accept the root faithfulness hypothesis with its correct consequences as the basis for NDEB.

\subsection{The part-of-speech effect}

We now turn to the question how the part-of-speech effect can be incorporated in the analysis. The basic observation is that nouns coalesce less than adjectives, just as nonderived forms coalesce less than derived forms. This might suggest that the two should receive parallel synchronic treatments, perhaps in terms of another specialized faithfulness constraint $\mathrm{FAITH}_{\text {noun }}$, parallel to $\mathrm{FAITH}_{\text {root }}$, following Smith (1997). However, on closer inspection, the evidence points at a different direction. In this section, we will show that while a noun faithfulness analysis is technically possible, a cophonology analysis gives an empirically equally good, formally simpler, and generally more plausible account of the facts.

Let us first see how far we can go with the noun faithfulness hypothesis. The most conservative move would be to add the constraint $\mathrm{FAITH}_{\text {noun }}$ into the existing partial ordering, with no additional rankings. Since we now have all the pieces of the analysis in place, we can compare the predicted probabilities to the observed frequencies. 
(40) $\mathrm{OBS}_{1} \%=$ the observed range of variation (10 groups)

$\mathrm{OBS}_{2} \%=$ the observed coalescence rate in the total corpus

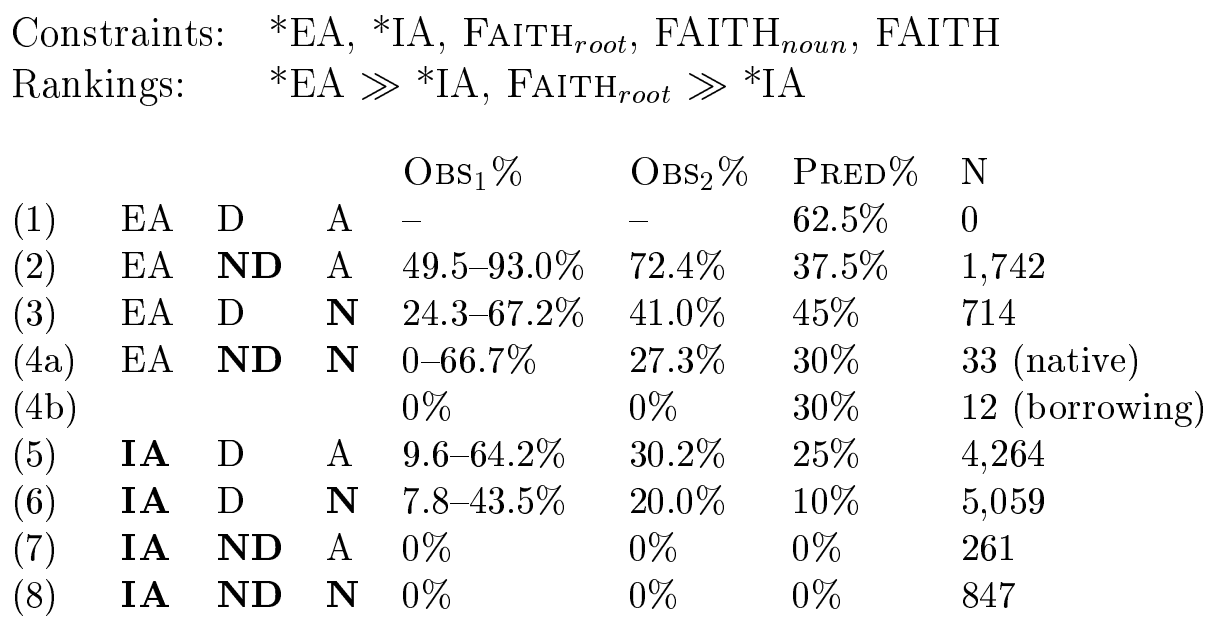

Two problems emerge. First, the grammar does not distinguish between native words and borrowings, which means that we predict the same numbers for both (4a) hopea hopee 'silver' and (4b) idea ${ }^{*}$ idee 'idea'. The question is how to capture increasingly smaller morphological subregularities and ultimately lexical idiosyncrasies in this framework. The obvious answer is cophonologies: some lexical items, or groups of lexical items, are affiliated with special rankings. Note that this does not mean choosing a ranking randomly: a lexeme-specific phonology is a subgrammar of the general phonology of the language. Put differently, lexeme-specific phonologies are more specific than the general phonology of the language. This corresponds to the intuitive notion that lexical exceptions add complexity to the grammar. Specific rankings that account for both native nouns and recent borrowings will be proposed shortly.

A more serious problem is that the predicted coalescence probabilities on lines (2) and (3) are the wrong way round: EA-final derived nouns (e.g. ove- $a$ 'door-PAR') are predicted to coalesce more than EA-final nonderived adjectives (e.g. makea 'sweet'), but in reality the opposite is the case. As for the corresponding IA-words on lines (6) and (7), here the predictions are the right way round. 


$$
\begin{array}{llll}
\mathrm{OBS}_{1} \% & \mathrm{OBS}_{2} \% & \text { PRED } \% & \mathrm{~N}
\end{array}
$$

2. $\begin{array}{lllllll}\text { EA ND A } & 49.5-93.0 \% & 72.4 \% & 37.5 \% & 1,742\end{array}$

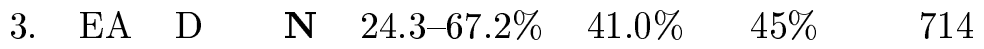

6. IA $\begin{array}{llllll}\text { IA } & \mathbf{N} & 7.8-43.5 \% & 20.0 \% & 10 \% & 5,059\end{array}$

7. IA ND A $0 \% \quad 0 \% \quad 0 \% \quad 261$

This problem is serious for two reasons. First, the empirical generalization is robust: nonderived EA-adjectives coalesce more than derived EA-nouns in all 10 varieties of Helsinki Finnish we have discussed: all three age-groups, all three social classes, both neighborhoods and both sexes. ${ }^{16}$ Second, the problem turns out technically hard to solve. What we need is a partially ordered grammar that guarantees the correct results in both (2)-(3) and $(6)-(7)$. Let us start by considering the first case. We must find a partial ordering that makes nonderived EA-adjectives (makea 'sweet, a.') coalesce more than derived EA-nouns (ove- $a$ 'door-PAR, n.'). Consider the schematic tableau in (42). No rankings are intended.

\begin{tabular}{|ll||ccccc|}
\hline & /Ove-a $/$ noun & ${ }^{*}$ EA & ${ }^{*}$ IA & FAITH $_{\text {root }}$ & FAITH $_{\text {noun }}$ & FAITH \\
\hline \hline 1a. & ove-a & $*$ & & & & \\
\hline 1b. & ove-e & & & & & $*$ \\
\hline \hline & /makea $/$ adj & ${ }^{*}$ EA & ${ }^{*}$ IA & FAITH $_{\text {root }}$ & FAITH $_{\text {noun }}$ & FAITH \\
\hline \hline 2a. & makea & $*$ & & & & \\
\hline 2b. & makee & & & $*$ & & $*$ \\
\hline
\end{tabular}

Since the constraint violations are identical except for $\mathrm{FAITH}_{\text {root }}$ and FAITH $_{\text {noun }}$, we can obtain the desired result by constructing a partial ordering where $\mathrm{FAITH}_{\text {noun }} \gg \mathrm{FAITH}_{\text {root }}$ holds in a larger number of tableaux than the reverse FAITH $_{\text {root }} \gg$ FAITH $_{\text {noun }}$.

Now, consider the second case. This time, we need to guarantee that derived IA-nouns (lasi-a 'glass-PAR, n.') coalesce more than nonderived IAadjectives (kauhia 'terrible, a.'), which in fact should never coalesce.

\footnotetext{
${ }^{16}$ The generalization holds even in the more fine-grained dialect taxonomy based on cross-classification by age (3), social class (3), neighborhood (2) and sex (2) which gives $3 \times 3 \times 2 \times 2=36$ groups of which we have representatives in 34 . Of these dialects, 32 conform to the generalization. The two exceptions are old middle-class Töölö males (makee $34.2 \%$, ove-e $36 \%$ ) and middle-aged upper middle class Töölö females (makee $31.9 \%$, ove-e $41.7 \%)$.
} 
(43)

\begin{tabular}{|ll||ccccc|}
\hline & /lasi-a/noun & $*$ EA & ${ }^{*}$ IA & FAITH $_{\text {root }}$ & FAITH $_{\text {noun }}$ & FAITH \\
\hline \hline 1a. & lasi-a & & $*$ & & & \\
\hline 1b. & lasi-i & & & & $*$ & $*$ \\
\hline & /kauhia/adj & $*$ EA & ${ }^{*}$ IA & FAITH $_{\text {root }}$ & FAITH $_{\text {noun }}$ & FAITH \\
\hline \hline 2a. & kauhia & & $*$ & & & \\
\hline 2b. & ${ }^{*}$ kauhii & & & $*$ & & $*$ \\
\hline
\end{tabular}

Again, the violations are identical except for FAITH $_{\text {root }}$ and FAITH $\mathrm{Foun}_{\text {no }}$. This time, we need a partial ordering where $\mathrm{FAITH}_{\text {root }} \gg \mathrm{FAITH}_{\text {noun }}$ holds in a larger number of tableaux than the reverse $\mathrm{FAITH}_{\text {noun }} \gg \mathrm{FAITH}_{\text {root }}$. But this contradicts the ranking established for the first case. We conclude that there is no partial ordering of these five constraints that would predict the observed pattern in both cases.

The most direct way to salvage the analysis is to invoke subtler constraints that refer to both phonology and morphology simultaneously. If we

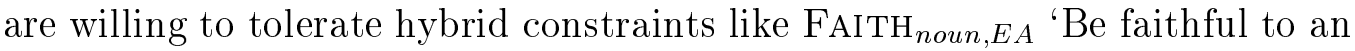
EA-final noun', the way is open to new and powerful descriptive possibilities. With such constraints, it is quite easy to construct a grammar that gets the quantitative predictions right in both cases. However, while this may be descriptive success, it comes at the price of having to posit different copies of $\mathrm{FAITH}_{\text {noun }}$ and $\mathrm{FAITH}_{\text {root }}$ for stems with different phonological shapes. Instead of mixing phonology and morphology in the constraints themselves, one would have expected phonology and morphology to interact through ranking, that being the mode of interaction native to Optimality Theory.

What casts even more doubt on the noun faithfulness explanation is that there is a plausible alternative available. Essentially, the problem we are faced with is that derived EA-nouns coalesce less than predicted. Could this be because of analogy with IA-nouns which resist coalescence for phonological reasons? Recall that this is the very explanation we invoked in order to account for the NDEB-effect in recently borrowed nonderived nouns (idea $\sim^{*} i d e e$ 'idea, n.'). The analogical explanation was motivated by quantitative facts: nonderived IA-nouns vastly outnumber nonderived EA-nouns in the dictionary (and as we can now see, also in usage), thus providing an attractive model for the EA-nouns to follow. The same quantitative explanation works here: derived IA-nouns are vastly more common in the corpus than derived EA-nouns. If this is correct, then Optimality Theory pointed us in the right direction: the failure to find a simple grammar to fit the 
facts was symptomatic of a misguided analysis. In short, the fact that Vowel Coalescence tends to be blocked in nouns cannot be taken as evidence for a universal constraint $\mathrm{FAITH}_{\text {noun }}$. Instead, it can be derived from two facts: (i) the vast majority of nouns disfavor coalescence for phonological reasons (the phonological majority effect) and (ii) nouns as a group tend to behave alike (analogy).

What, then, is the correct synchronic analysis of the part-of-speech effect?

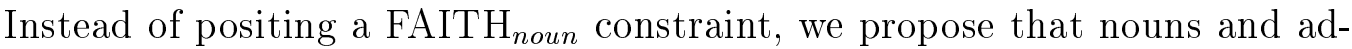
jectives subscribe to two minimally different subgrammars within the phonology of Finnish. As we have seen, the choice is sometimes lexeme-specific: the noun hopea hopee 'silver, n.' coalesces, but the noun idea/*idee 'idea, n.' does not. However, as a rule, lexical items do not exercise their free will with abandon. Rather, nouns tend to cluster together phonologically; the same holds of adjectives. We can thus dispense with the constraint $\mathrm{FAITH}_{\text {noun }}$ and revert to the simpler four-constraint grammar in (36). Under this new analysis, we assign a special binary ranking to the category Noun and the reverse ranking to the category Adjective. The resulting Noun Grammar and Adjective Grammar are both partial orders. They are more specific (by one binary ranking) than Finnish phonology of which they are subgrammars.

(44) The cophonology analysis:
a. Finnish phonology:
$* \mathrm{EA} \gg * \mathrm{IA} \mathrm{FAITH}_{\text {root }} \gg * \mathrm{IA}$
b. Noun Grammar:
Finnish phonology $\cup$ FAITH $_{\text {root }} \gg{ }^{*} \mathrm{EA}$
c. Adjective Grammar:
Finnish phonology $\cup * \mathrm{EA} \gg \mathrm{FAITH}_{\text {root }}$

This simple analysis (four constraints, four binary rankings) yields a reasonably good quantitative approximation of the behavior of nouns and adjectives in the entire corpus.

$\begin{array}{llllllll} & & & & \text { OBS }_{1} \% & \text { OBS }_{2} \% & \text { PRED\% } & \mathrm{N} \\ (1) & \text { EA } & \text { D } & \text { A } & - & - & 75 \% & 0 \\ (2) & \text { EA } & \text { ND } & \text { A } & 49.5-93.0 \% & 72.4 \% & 75 \% & 1,742 \\ (3) & \text { EA } & \text { D } & \text { N } & 24.3-67.2 \% & 41.0 \% & 50 \% & 714 \\ (4 \mathrm{a}) & \text { EA } & \text { ND } & \text { N } & 0-66.7 \% & 27.3 \% & 0 \% & 33 \text { (native) } \\ (4 b) & & & & 0 \% & 0 \% & 0 \% & 12 \text { (borrowing) } \\ (5) & \text { IA } & \text { D } & \text { A } & 9.6-64.2 \% & 30.2 \% & 25 \% & 4,264 \\ (6) & \text { IA } & \text { D } & \text { N } & 7.8-43.5 \% & 20.0 \% & 25 \% & 5,059 \\ (7) & \text { IA } & \text { ND } & \text { A } & 0 \% & 0 \% & 0 \% & 261 \\ (8) & \text { IA } & \text { ND } & \text { N } & 0 \% & 0 \% & 0 \% & 847\end{array}$


In the case of nonderived EA-final nouns (4ab), the grammar predicts the NDEB pattern of recent borrowings (idea $\left.\sim^{*} i d e e\right)$. The four native roots (33 tokens) that do coalesce, namely hopea 'silver', aukea 'opening', häpeä 'shame' and lipe ä 'lye', are best treated in terms of lexeme-specific cophonologies, i.e. as being lexically affiliated with the Adjective Grammar. Note that this is not an option for IA-nouns: phonology correctly dictates that coalescence is categorically blocked in all nonderived IA-words, nouns as well as adjectives.

More generally, cophonologies seem the right way of handling the synchronic complications due to lexical diffusion (Wang 1969, Wang 1977, Labov 1994, Kiparsky 1989, Kiparsky 1995), a species of analogical change that proceeds lexical item by lexical item, yet crucially in a phonologically constrained manner. The Finnish case is typical: the four native EA-stems have not yet caught up with the recent analogical trend, and perhaps never will, whereas incoming words like idea unhesitatingly subscribe to the noun grammar.

The cophonology theory of lexical diffusion is compatible with Kiparsky's (1995) theory based on Lexical Morphology and Phonology, at least in spirit. For Kiparsky, analogical change entails the simplification of lexical entries on one hand and the generalization of lexical rules on the other. In the present theory, the same effect is obtained by the elimination of parochial rankings. For example, bringing the four exceptional hopea-nouns in line with other nouns could be accomplished by eliminating the lexeme-specific ranking *EA $\gg$ FAITH $_{\text {root }}$ (the "adjective ranking") from four lexical items, which would cause them to default to the reverse ranking they have in virtue of being nouns, given the reasonable assumption that lexeme-specific information overrides information inherited from part of speech.

Let us now summarize the main results. We have found that the blocking of Vowel Coalescence can be traced back to three independent factors: vowel height, (non)derivedness and part of speech. These effects add up and in the extreme case result in categorical blocking. Quantitative evidence suggests that the derived environment effect and the part of speech effect are fundamentally different: in our analysis, the derived environment effect follows from the (presumably universal) phonological constraint FAITH $_{\text {root }}$, whereas the part-of-speech effect is an instance of analogy, synchronically implemented by means of the very different device of cophonologies.

It remains to be seen whether MORPHOLOGICAL CONSTITUENT STRUCTURE (root, stem, word) can be universally connected with systematic quantitative effects that are independent of phonology, and whether the effects 
of MORPHOLOGICAL AND LEXICAL CATEGORY (part of speech, lexical identity) can be universally shown to have less systematic phonology-dependent quantitative reflexes. Such a discovery would constitute quantitative evidence for constraints on constituency such as ALIGN and FAITH root $_{\text {, inter- }}$ spersed among the purely phonological constraints in the partial ordering, and against constraints like $\mathrm{FAITH}_{\text {noun }}$ as well as lexeme-specific constraints (Hammond 1995, Russell 1995, Russell 1999, Myers 1999). The one substantial piece of empirical evidence I know of is consistent with this hypothesis. In English t,d-Deletion (Guy 1991), we find a robust statistical correlation between depth of morphological constituency and $t, d$-deletion rate. However, since sufficiently detailed quantitative studies of phonology/morphology interaction are scarce, this generalization must remain tentative.

\section{A note on underspecification}

We are now ready to consider yet another general approach to blocking effects: underspecification. This approach was originally proposed by Kiparsky (1993a) in connection with NDEB-effects and generalized to other types of blocking by Inkelas (to appear). Kiparsky's proposal is stated in (46):

(46) NDEB is a property of structure-building rules operating on underspecified representations (Kiparsky 1993a)

In other words: if the target of a structure-building rule is underspecified, the rule can apply and the result is an alternation. If the target of a structurebuilding rule is prespecified, the rule cannot apply because it is defeated by the pre-existing representation and the result is blocking.

As Sharon Inkelas has pointed out to me, this approach is perfectly compatible with Optimality Theory. For a detailed demonstration that the approach extends to blocking effects of various kinds, see Inkelas to appear. For Finnish, suppose that the nonalternating /a, ä/-vowels are prespecified as [+low], whereas their alternating counterparts are underspecified for height. Following Inkelas, we could further suppose that the grammar permits underspecification only if an alternation has been observed and that the speaker assumes that an observed sequence is nonalternating until proven otherwise. It would be fairly easy to reformulate the present analysis along these lines. All we need to do is change our assumptions about underlying forms on a lexeme-by-lexeme basis and substitute NoLongVowel (Rosenthall 1994) 
for FAITH; both constraints essentially say "don't coalesce". Partial ordering would still remain a necessary part of the analysis because underspecification cannot by itself handle quantitative facts. However, given the present understanding, an underspecification analysis does not seem warranted for reasons to which we will now turn.

First, we observe that underspecification/prespecification would not improve the analysis in any way. It would not capture any new empirical facts, neither would it result in a simpler analysis. What can be derived with underspecification can also be derived without it. In other words, underspecification is redundant.

Second, as pointed out by Inkelas, underspecification/prespecification provides a uniform approach to all blocking effects. However, as we have seen, not all blocking effects are alike. Blocking of the "nonderived environment type" is a well-known cross-linguistic fact; to capture it we posited the

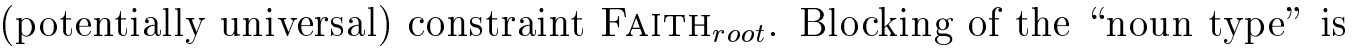
arguably a Finnish-specific fact that results from the analogical influence of the statistical majority of nouns. Blocking of the "vowel height type" may well have a phonetic explanation. All three blocking phenomena can undoubtedly be described as underspecification, but in reality they have quite different sources. By adopting underspecification, we would simply end up stipulating that most roots, nouns and $i a$-sequences tend to have a prespecified /a/, whereas most suffixes, adjectives and $e a$-sequences tend to have an underspecified /A/. All these facts should of course follow from independent considerations, but if they do, it is not clear why underspecification is needed at all. In short, underspecification/prespecification - while compatible with OT - makes all kinds of blocking look the same, yet different kinds of blocking originate in quite different ways, and it is precisely these differences that are theoretically interesting.

Third, following Inkelas, we might propose that underspecification is possible only if an alternation has been observed, else full specification is assumed. However, as we have been observing throughout this paper, the fact that an alternation is observed in context $\mathrm{A}$, but not in context $\mathrm{B}$, is not an historical accident, but something that follows from the grammar itself, at least in part. Again, while underspecification can describe the facts, it adds little to our understanding of why alternations occur in certain environments, but are blocked in others.

Fourth, an underspecification analysis of Vowel Coalescence is inconsistent with Kiparsky's (1993a) original analysis where he argues that the very 
optionality of coalescence provides evidence for full specification. In contrast, an underspecification analysis must assume a default rule (or something equivalent) that optionally inserts the feature $[+$ low $]$ to word-final vowels underspecified for height in cases of non-coalescence, i.e. /makeA/ 'sweet, a.' $\rightarrow$ makea. However, evidence from the spontaneous nativization of foreign names that end in a consonant seems to imply that the unmarked height value assigned to epenthetic vowels is [+high], e.g. Aaroni (Aaron), Milleri (Miller), Pullumi (Pullum), Vitteni (Witten), not [+low], another potential problem for the underspecification analysis.

In sum, while an underspecification analysis inspired by Kiparsky (1993a) is clearly compatible with Optimality Theory, as demonstrated by Inkelas (to appear), Vowel Coalescence in colloquial Helsinki Finnish does not provide evidence for underspecification.

\section{On the limitations of this study}

Finally, a comment on the limitations of the present study is due. Our quantitative results are preliminary in two respects. First, only -ea and - $i a$ stems have been considered. The reason for choosing these two was that they are the most frequent of the vowel sequences subject to coalescence. However, Paunonen's study suggests that including -oa, - $\ddot{o},-u a$ and $-y \ddot{a}$ will not drastically change the general picture.

Second, each category contains words of varying lengths. For example, among IA-final derived adjectives we find both suur- $i$ - $a$ 'big-PL-PAR' (three syllables) and semmos- $i$ - $a$ 'such-PL-PAR' (four syllables). The difference is potentially relevant because word length affects secondary stress placement which in turn affects coalescence. The prediction is that coalescence should be blocked if secondary stress falls on either vowel. In súu.r-i.-a there is no secondary stress; in sém.mo.s-i-a secondary stress falls on the third syllable, although perhaps only postlexically (Anttila 1997b), and the matter is further complicated by the fact that secondary stress is itself optional in certain circumstances (Keyser and Kiparsky 1984). It will be interesting to see whether including the secondary stress factor in the analysis results in even more accurate quantitative predictions. 


\section{Conclusion}

In this paper, we have examined a peculiar case of nonderived environment blocking: optional Vowel Coalescence (VC) in Colloquial Helsinki Finnish. Its theoretical significance lies in the fact that it runs counter to all the bestknown explanations of derived environment behavior. As Kiparsky (1993a) already showed, VC is incompatible with the Strict Cycle Condition (Mascaró 1976) and the Elsewhere Condition (Kiparsky 1982) because it is both cyclic and lexical, yet applies in nonderived environments. We may now further add that $\mathrm{VC}$ is also incompatible with the Revised Alternation Condition (Kiparsky 1973): VC is a nonautomatic optional neutralization rule which is blocked in nonderived environments in certain phonological contexts, but not in others. Finally, VC is also inconsistent with the proposal that NDEB is a property of structure-building rules operating on underspecified representations: being optional, it must be structure-changing (Kiparsky 1993a:287).

What the evidence ultimately shows is that derived environment behavior cannot be tied to phonological rules of any kind. The reason is simple: the very same rule may show NDEB in certain contexts, but not in others, depending on global grammatical considerations. The old explanations were clearly in the right direction, but time and again it turned out that NDEB was tied to a particular rule type only approximately, if at all. It seems now that the failure to unify NDEB effects was mainly due to the decision to take rules, i.e. specific phonological processes, as the locus of explanation.

In this case at least, Optimality Theory leads one to look for explanations in the right direction: since Optimality Theory does not even recognize rules as theoretical entities, it suggests that the explanation for NDEB must be found from global interactions of markedness and faithfulness. What is more, Optimality Theory also provides a simple way of deriving both the categorical and quantitative blocking effects from one and the same grammar. As has been shown here and elsewhere (Anttila 1997a, Anttila 1997b, Anttila and Cho 1998), quantitative tendencies fall within the scope of optimalitytheoretic explanation once we generalize the theory from total to partial orderings, which simply means removing the requirement of connectedness from grammatical theory. 


\section{Appendix}

The linguistic reality of the three structural hierarchies that determine Vowel Coalescence is corroborated by the observation that they hold without exception, not only across age groups, but also across social groups, neighborhoods and sexes.

As for social class, Paunonen follows the official three-way classification system used by the City of Helsinki, with a minor modification: Class I only includes speakers with academic degrees and their children currently in junior college; Class III only includes those working class speakers whose formal education is limited to primary school and possibly vocational training. Of the two neighborhoods, Töölö is a traditional upper middle class neighborhood, Sörnäinen a traditional working class neighborhood.

(47) Social class I:

\begin{tabular}{|ll|ll|ll|}
\hline & & $-e a$ & & $-i a$ & \\
\hline $\mathrm{N}$ & $\mathrm{ND}$ & $14.3 \%$ & $(2 / 14)$ & $0 \%$ & $(0 / 310)$ \\
& $\mathrm{D}$ & $31.9 \%$ & $(69 / 216)$ & $10.6 \%$ & $(180 / 1,697)$ \\
\hline $\mathrm{A}$ & $\mathrm{ND}$ & $62.5 \%$ & $(353 / 565)$ & $0 \%$ & $(0 / 78)$ \\
& $\mathrm{D}$ & - & - & $22.3 \%$ & $(332 / 1,488)$ \\
\hline
\end{tabular}

(48) Social class II:

\begin{tabular}{|ll|ll|ll|}
\hline & & $-e a$ & & $-i a$ & \\
\hline $\mathrm{N}$ & $\mathrm{ND}$ & $11.8 \%$ & $(4 / 34)$ & $0 \%$ & $(0 / 339)$ \\
& $\mathrm{D}$ & $39.4 \%$ & $(109 / 277)$ & $22.7 \%$ & $(402 / 1,768)$ \\
\hline $\mathrm{A}$ & $\mathrm{ND}$ & $72.1 \%$ & $(473 / 656)$ & $0 \%$ & $(0 / 117)$ \\
& $\mathrm{D}$ & - & - & $31.5 \%$ & $(473 / 1,500)$ \\
\hline
\end{tabular}

(49) Social class III:

\begin{tabular}{|ll|ll|ll|}
\hline & & $-e a$ & & $-i a$ & \\
\hline N & ND & $23.1 \%$ & $(3 / 13)$ & $0 \%$ & $(0 / 198)$ \\
& D & $52.0 \%$ & $(115 / 221)$ & $27.1 \%$ & $(432 / 1,594)$ \\
\hline A & ND & $83.7 \%$ & $(436 / 521)$ & $0 \%$ & $(0 / 66)$ \\
& D & - & - & $37.9 \%$ & $(484 / 1,276)$ \\
\hline
\end{tabular}


(50) Töölö (trad. upper middle class neighborhood):

\begin{tabular}{|ll|ll|ll|}
\hline & & $-e a$ & & $-i a$ & \\
\hline $\mathrm{N}$ & $\mathrm{ND}$ & $12.5 \%$ & $(4 / 32)$ & $0 \%$ & $(0 / 503)$ \\
& $\mathrm{D}$ & $39.9 \%$ & $(140 / 351)$ & $16.3 \%$ & $(425 / 2,601)$ \\
\hline $\mathrm{A}$ & $\mathrm{ND}$ & $68.3 \%$ & $(602 / 882)$ & $0 \%$ & $(0 / 133)$ \\
& $\mathrm{D}$ & - & - & $24.7 \%$ & $(537 / 2,176)$ \\
\hline
\end{tabular}

(51) Sörnäinen (trad. working class neighborhood):

\begin{tabular}{|ll|ll|ll|}
\hline & & $-e a$ & & $-i a$ & \\
\hline $\mathrm{N}$ & $\mathrm{ND}$ & $17.2 \%$ & $(5 / 29)$ & $0 \%$ & $(0 / 344)$ \\
& $\mathrm{D}$ & $42.1 \%$ & $(153 / 363)$ & $24.0 \%$ & $(589 / 2,458)$ \\
\hline $\mathrm{A}$ & $\mathrm{ND}$ & $76.7 \%$ & $(660 / 860)$ & $0 \%$ & $(0 / 128)$ \\
& $\mathrm{D}$ & - & - & $36.0 \%$ & $(752 / 2,088)$ \\
\hline
\end{tabular}

(52) Female:

\begin{tabular}{|ll|ll|ll|}
\hline & & $-e a$ & & $-i a$ & \\
\hline $\mathrm{N}$ & $\mathrm{ND}$ & $22.5 \%$ & $(9 / 40)$ & $0 \%$ & $(0 / 437)$ \\
& $\mathrm{D}$ & $41.7 \%$ & $(182 / 436)$ & $19.2 \%$ & $(519 / 2,700)$ \\
\hline $\mathrm{A}$ & $\mathrm{ND}$ & $76.6 \%$ & $(913 / 1,192)$ & $0 \%$ & $(0 / 141)$ \\
& $\mathrm{D}$ & - & - & $30.0 \%$ & $(688 / 2,297)$ \\
\hline
\end{tabular}

(53) Male:

\begin{tabular}{|ll|ll|ll|}
\hline & & $-e a$ & & $-i a$ & \\
\hline $\mathrm{N}$ & $\mathrm{ND}$ & $0 \%$ & $(0 / 21)$ & $0 \%$ & $(0 / 410)$ \\
& $\mathrm{D}$ & $39.9 \%$ & $(111 / 279)$ & $21.0 \%$ & $(495 / 2,359)$ \\
\hline $\mathrm{A}$ & $\mathrm{ND}$ & $63.5 \%$ & $(349 / 550)$ & $0 \%$ & $(0 / 120)$ \\
& $\mathrm{D}$ & - & - & $30.5 \%$ & $(601 / 1,967)$ \\
\hline
\end{tabular}




\section{Bibliography}

Alderete, John. 1999. Morphologically Governed Accent in Optimality Theory. Doctoral dissertation, University of Massachussetts, Amherst. ROA-309.

Anttila, Arto. 1997a. Deriving variation from grammar. In Frans Hinskens, Roeland van Hout, and Leo Wetzels (eds.), Variation, Change and Phonological Theory, 35-68. Amsterdam/Philadelphia, John Benjamins Publishing Company. Also: ROA-63.

Anttila, Arto. 1997b. Variation in Finnish Phonology and Morphology. Doctoral dissertation, Stanford University, Stanford, California.

Anttila, Arto. 2000. Morphologically conditioned phonological alternations. Ms. Boston University.

Anttila, Arto, and Young-mee Cho. 1998. Variation and change in Optimality Theory. Lingua 104, 31-56. Special issue on Optimality Theory.

Anttila, Arto, and Anthi Revithiadou. 2000. Variation in Allomorph Selection. Proceedings of NELS 30.

Beckman, Jill N. 1998. Positional Faithfulness. Doctoral dissertation, University of Massachusetts, Amherst.

Burzio, Luigi. 1998. Cycles, Non-Derived Environment Blocking, and Correspondence. Ms., Johns Hopkins University.

Cedergren, Henrietta J., and David Sankoff. 1974. Variable rules: Performance as a statistical reflection of competence. Language 50, 333-55.

Guy, Gregory R. 1991. Explanation in variable phonology. Language Variation and Change 3, 1-22.

Haas, Wim de. 1988. A Formal Theory of Vowel Coalescence. Dordrecht Holland/Providence RI - USA, Foris publications.

Hammond, Michael. 1995. There is no lexicon! ROA-43.

Hualde, José. 1989. The strict cycle condition and noncyclic rules. Linguistic Inquiry 20, 675-680. 
Inkelas, Sharon. 1998. The theoretical status of morphologically conditioned phonology: a case study of dominance effects. In Gert Booij and Jaap van Marle (eds.), Yearbook of Morphology 1997, 121-155. Kluwer, Kluwer Academic Publishers.

Inkelas, Sharon. to appear. Phonotactic blocking through structural immunity. In B. Stiebels and D. Wunderlich (eds.), Proceedings of the Lexicon in Focus Workshop. University of Düsseldorf. Also: ROA-366.

Inkelas, Sharon, Orhan Orgun, and Cheryl Zoll. 1997. The implications of lexical exceptions for the nature of grammar. In Iggy Roca (ed.), Derivations and Constraints in Phonology, 393-418. Oxford University Press.

Itô, Junko, and Armin Mester. 1995a. The core-periphery structure in the lexicon and constraints on re-ranking. In Jill N. Beckman, Laura Walsh Dickey, and Suzanne Urbanczyk (eds.), Papers in Optimality Theory, 181-210. University of Massachusetts, Amherst, GLSA.

Itô, Junko, and Armin Mester. 1995b. Japanese phonology. In John A. Goldsmith (ed.), The Handbook of Phonological Theory, 817-38. Oxford, Blackwell.

Itô, Junko, and Armin Mester. 1998. The phonological lexicon. In Natsuko Tsujimura (ed.), A Handbook of Japanese Linguistics. Oxford, Blackwell.

Karlsson, Göran. 1978. Kolmi- ja useampitavuisten nominivartaloiden loppuA:n edustuminen monikon $i: n$ edellä [The realization of the final A of trisyllabic and longer nominal stems before the plural $i]$. In $R a k_{\text {- }}$ enteita. Juhlakirja Osmo Ikolan 60-vuotispäiväksi, 6.2.1978., 86-99. Turun Yliopiston suomalaisen ja yleisen kielitieteen laitos.

Keyser, Samuel Jay, and Paul Kiparsky. 1984. Syllable structure in Finnish phonology. In Mark Aronoff and Richard T. Oehrle (eds.), Language Sound Structure. Studies in Phonology Presented to Morris Halle by His Teacher and Students, 7-31. Cambridge, Mass., MIT Press.

Kiparsky, Paul. 1973. Phonological representations. In Osamu Fujimura (ed.), Three Dimensions of Linguistic Theory. Tokyo, TEC. 
Kiparsky, Paul. 1982. Lexical morphology and phonology. In I.-S. Yang (ed.), Linguistics in the Morning Calm. Seoul, Hanshin.

Kiparsky, Paul. 1989. Phonological change. In Frederick Newmeyer (ed.), Linguistics: The Cambridge Survey, 363-415. Cambridge, Cambridge University Press.

Kiparsky, Paul. 1993a. Blocking in nonderived environments. In Sharon Hargus and Ellen Kaisse (eds.), Phonetics and Phonology, Volume 4: Studies in Lexical Phonology, 277-313. San Diego, California, Academic Press.

Kiparsky, Paul. 1993b. Variable rules. Handout distributed at the Rutgers Optimality Workshop (ROW1).

Kiparsky, Paul. 1995. The phonological basis of sound change. In John A. Goldsmith (ed.), The Handbook of Phonological Theory, 640-70. Oxford, Blackwell.

Kiparsky, Paul. in press. Paradigm Effects and Opacity. Stanford, California, CSLI Publications.

Labov, William. 1994. Principles of Linguistic Change: Internal Factors. Oxford, UK, and Cambridge, USA, Blackwell.

Łubowicz, Anna. 1998. Derived environment effects in OT. Ms., University of Massachusetts, Amherst.

Mascaró, Joan. 1976. Catalan Phonology and the Phonological Cycle. Doctoral dissertation, Massachusetts Institute of Technology.

McCarthy, John, and Alan Prince. 1993. Prosodic Morphology I: Constraint Interaction and Satisfaction. University of Massachusetts, Amherst, and Rutgers University.

McCarthy, John, and Alan Prince. 1995. Faithfulness and reduplicative identity. In Jill N. Beckman, Laura Walsh Dickey, and Suzanne Urbanczyk (eds.), Papers in Optimality Theory, 249-384. UMass, Amherst, GLSA.

Mohanan, K.P. 1986. The Theory of Lexical Phonology. Dordrecht, Reidel. 
Myers, James. 1999. Lexical phonology and the lexicon. ROA-330.

Nagy, Naomi, and William Reynolds. 1997. Optimality theory and variable word-final deletion in Faetar. Language Variation and Change 9(1), $37-55$.

Orgun, Cemil Orhan. 1996. Sign-Based Morphology and Phonology with special attention to Optimality Theory. Doctoral dissertation, Department of Linguistics, University of California, Berkeley. ROA-171.

Paunonen, Heikki. 1995. Suomen kieli Helsingissä. Huomioita Helsingin puhekielen historiallisesta taustasta ja nykyvariaatiosta. Helsinki, Helsingin yliopiston suomen kielen laitos. [The Finnish language in Helsinki. Observations on the historical background of and current variation in spoken Helsinki Finnish.].

Prince, Alan, and Paul Smolensky. 1993. Optimality Theory: Constraint Interaction in Generative Grammar. Rutgers University, New Brunswick, and University of Colorado, Boulder.

Pulleyblank, Douglas. 1988. Vocalic underspecification in Yoruba. Linguistic Inquiry 19(2), 233-270.

Rapola, Martti. 1966. Suomen kielen äännehistorian luennot [Lectures on the Historical Phonology of Finnish]. Helsinki, Suomalaisen Kirjallisuuden Seura.

Reynolds, William Thomas. 1994. Variation and Phonological Theory. Doctoral dissertation, University of Pennsylvania.

Ringen, Catherine O., and Orvokki Heinämäki. 1999. Variation in Finnish vowel harmony. Natural Language and Linguistic Theory 303-37.

Rosenthall, Samuel. 1994. Vowel/Glide Alternations in a Theory of Constraint Interaction. Doctoral dissertation, University of Massachussetts, Amherst. ROA-126.

Rubach, Jerzy. 1984. Cyclic and Lexical Phonology: The Structure of Polish. Dordrecht, Foris.

Russell, Kevin. 1995. Morphemes and candidates in Optimality Theory. ROA-44. 
Russell, Kevin. 1999. MOT: Sketch of an OT approach to morphology [DRAFT]. ROA-352.

Sadeniemi, Matti (ed.). 1973. Nykysuomen sanakirja [Dictionary of Modern Finnish]. Porvoo, Finland, Werner Söderström Osakeyhtiö.

Smith, Jennifer L. 1997. Noun faithfulness: On the privileged status of nouns in phonology. ROA-242.

Smolensky, Paul. 1995. On the internal structure of the constraint component Con of UG. Handout of a talk given at UCLA, April 7, 1995; Department of Cognitive Science, Johns Hopkins University.

Wang, William S.-Y. 1969. Competing changes as a cause of residue. Language 45, 9-25. Reprinted in Baldi, Philip and Ronald N. Werth, eds., 1978. Readings in Historical Phonology. University Park and London: The Pensylvania State University Press.

Wang, William S.-Y. (ed.). 1977. The Lexicon in Phonological Change. Mouton. The Hague. 